\title{
BMJ Open Cost-effectiveness of milk powder fortified with potassium to decrease blood pressure and prevent cardiovascular events among the adult population in China: a Markov model
}

\author{
Livia Dainelli, ${ }^{1}$ Tingting $\mathrm{Xu},{ }^{2,3} \mathrm{Min} \mathrm{Li},{ }^{4}$ Diane Zimmermann, ${ }^{1}$ Hai Fang, ${ }^{2}$ \\ Yangfeng Wu, ${ }^{4,5,6}$ Patrick Detzel $^{1}$
}

To cite: Dainelli L, Xu T, Li M, et al. Cost-effectiveness of milk powder fortified with potassium to decrease blood pressure and prevent cardiovascular events among the adult population in China: a Markov model. BMJ Open 2017;7:e017136. doi:10.1136/ bmjopen-2017-017136

\section{- Prepublication history for} this paper is available online. To view these files please visit the journal online (http://dx.doi. org/10.1136/bmjopen-2017017136).

Received 4 April 2017

Revised 6 July 2017

Accepted 7 July 2017

\section{CrossMark}

${ }^{1}$ Nestlé Research Center, Lausanne, Switzerland

${ }^{2}$ China Center for Health Development Studies, Peking University, Beijing, China ${ }^{3}$ Department of Health Policy and Administration, Peking University School of Public Health, Beijing, China ${ }^{4}$ Department of Epidemiology and Biostatistics, Peking University School of Public Health, Beijing, China

${ }^{5}$ The George Institute for Global Health, Peking University Health Science Centre, Beijing, China

${ }^{6}$ Peking University Clinical Research Institute, Beijing, China

Correspondence to

Dr Patrick Detzel;

patrick.detzel@rdls.nestle.com

\section{ABSTRACT}

Objective To model the long-term cost-effectiveness of consuming milk powder fortified with potassium to decrease systolic blood pressure (SBP) and prevent cardiovascular events.

Design A best case scenario analysis using a Markov model was conducted.

Participants $8.67 \%$ of $50-79$ year olds who regularly consume milk in China, including individuals with and without a prior diagnosis of hypertension.

Intervention The model simulated the potential impact of a daily intake of two servings of milk powder fortified with potassium (+700 mg/day) vs the consumption of a milk powder without potassium fortification, assuming a market price equal to 0.99 international dollars (intl\$; the consumption of a milk powder without potassium fortification, assuming a market price equal to int $\$ 0.99$ for the latter and to intl\$1.12 for the first $(+13.13 \%)$. Both deterministic and probabilistic sensitivity analyses were conducted to test the robustness of the results.

Main outcome measures Estimates of the incidence of cardiovascular events and subsequent mortality in China were derived from the literature as well as the effect of increasing potassium intake on blood pressure. The incremental cost-effectiveness ratio (ICER) was used to determine the cost-effectiveness of a milk powder fortified with potassium taking into consideration the direct medical costs associated with the cardiovascular events, loss of working days and health utilities impact.

Results With an ICER equal to int\$4711.56 per QALY (quality-adjusted life year) in the best case scenario and assuming $100 \%$ compliance, the daily consumption of a milk powder fortified with potassium shown to be a cost-effective approach to decrease SBP and reduce cardiovascular events in China. Healthcare savings due to prevention would amount to int $\$ 8.41$ billion. Sensitivity analyses showed the robustness of the results.

Conclusion Together with other preventive interventions, the consumption of a milk powder fortified with potassium could represent a cost-effective strategy to attenuate the rapid rise in cardiovascular burden among the 50-79year olds who regularly consume milk in China.
Strengths and limitations of this study

- This is the first study to evaluate the costeffectiveness of a food fortified with potassium to prevent cardiovascular diseases in China.

- A conservative approach was adopted, including only stroke and myocardial infarction among the possible cardiovascular events.

- This analysis was based on data reported in the literature rather than data from real cases.

- In order to extend our results to a national level, we assumed that the incidence and costs related to cardiovascular events were the same across China.

\section{INTRODUCTION}

Cardiovascular diseases (CVD) are the leading cause of premature death and disability worldwide: more people die annually from CVD than from any other cause. ${ }^{12}$

China is not unique in that respect and has a very high burden from CVD. ${ }^{34}$ Among the individual modifiable risk factors, the most important in China is high blood pressure. ${ }^{5}$ Hypertension is a serious health issue which has significantly increased over the past few decades. In 2010, the prevalence of hypertension was estimated at $34 \%$ of the adult population (35\% in men and $32 \%$ in women $)^{4}$ with no signs of decline. ${ }^{6}$ The excessive dietary salt consumption (eg, in rural China, salt intake can be as high as $12-15 \mathrm{~g} /$ day $)^{7}$ is one of the major causes of hypertension and could partly explain why, among other reasons (eg, obesity, smoking and air pollution), the Chinese population has a higher overall stroke incidence compared with Caucasians. ${ }^{8-10}$ In China, $20 \%-41 \%$ of deaths are due to cardiovascular episodes ${ }^{211}$ and this percentage is likely to increase resulting in 21.3 million additional cardiovascular events 
and 7.7 million deaths from 2010 to 2030 , based on population ageing and growth alone. ${ }^{12} 13$

The financial burden from CVD is substantial to both patients and the healthcare system. In 2011 alone, almost 13 million patients in China were hospitalised for CVD, with total hospitalisation expenditures equalling $¥ 40$ billion (international dollar (intl\$) 11.36 billion at a conversion rate of intl $\$ 1.00=3.52 ¥),{ }^{14}$ which corresponded to $1.64 \%$ of the national health expenditures. ${ }^{11}$ The total amount of the annual direct costs are estimated to be more than US $\$ 40$ billion, the equivalent of $4 \%$ of China's gross national income, with indirect costs more than doubling the direct costs. ${ }^{15}$

In order to decrease systolic blood pressure (SBP), the WHO guidelines recommend to decrease sodium intake to less than $2000 \mathrm{mg} /$ day and increase potassium intake to at least $90 \mathrm{mmol}$ or $3510 \mathrm{mg} /$ day. ${ }^{16}$ Many studies have shown that reducing sodium intake in China would be an effective strategy, ${ }^{17}$ and recent studies have shown that increased potassium intake can benefit endothelial function, ${ }^{18}$ which is correlated with future cardiovascular events. ${ }^{19}$

This study aims to specifically evaluate the cost-effectiveness of increasing potassium intake $(+700 \mathrm{mg}$ /day) to lower SBP, and, consequently, the risk of CVD among the 50-79year olds who regularly consume milk in China via the consumption of a milk powder product fortified with potassium.

\section{METHODS}

The cost-effectiveness of a milk powder product fortified with potassium was estimated using TreeAge Pro 2015. We hypothesised that an additional potassium intake of $700 \mathrm{mg}$ /day would reduce the burden of disease related to CVD events due to the lowering effect of potassium intake on SBP.

\section{Baseline potassium intake}

Data from the 2009 China Health and Nutrition Survey $(\mathrm{CHNS}){ }^{20}$ were used to assess the baseline distribution of potassium intake among adults in nine provinces. Since individual-level data are distributed free of charge via the web, no agreement was required. Crème Nutrition, ${ }^{21}$ a scientific, cloud-based software service designed to analyse dietary intakes of foods and nutrients, was used to estimate the baseline potassium dietary intake. In their unpublished report, final outcome of a consultancy for Nestlé, the baseline potassium intake of the Chinese population aged over 45 years was $1781( \pm 9.95) \mathrm{mg} /$ day (figure 1). No permission to publish was needed.

\section{Potassium effect on the SBP}

We relied on the literature to estimate the effect of increasing potassium intake on SBP. Potassium supplementation is associated with a reduction of blood pressure and the effect size may vary depending on different factors. $^{22-26}$ For our model, we relied on one human

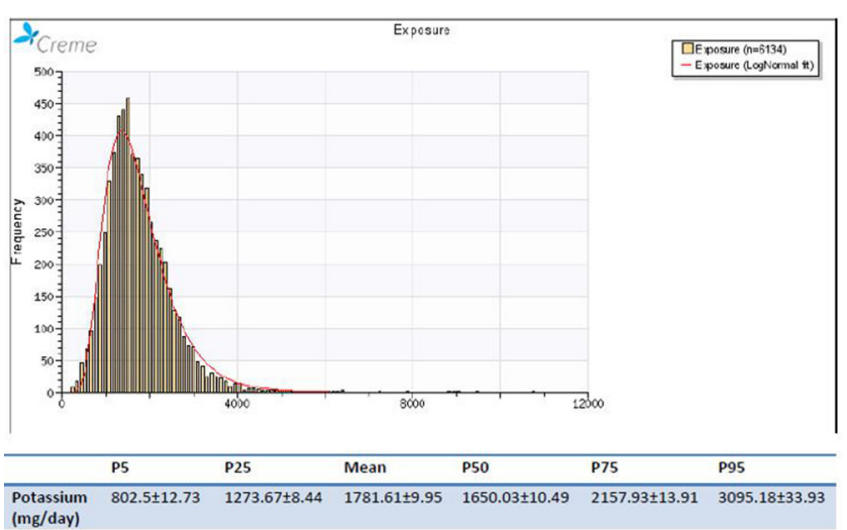

Figure 1 Baseline daily potassium intakes ( $\mathrm{mg} /$ day) from the total diet in the Chinese population aged over 45 years. Mean is the average of intake values for all individuals within the target population; P25, P50, P75 and P95 are percentiles and represent the values of intake below which the $25 \%, 50 \%$, $75 \%$ and $95 \%$ of the analysed population, respectively, falls. WHO guidelines recommend a potassium intake to at least $90 \mathrm{mmol}$ or $3510 \mathrm{mg} /$ day for adults. Source: Creme Global.

intervention study conducted in China on a heterogeneous population (normotensive, prehypertensive and hypertensive), where the subjects were given $60 \mathrm{mmol} /$ day via potassium chloride tablets. ${ }^{27}$ Compliance among subjects, measured using 24 hours urine samples and assuming $80 \%$ recovery, indicated a dietary intake of about $26 \mathrm{mmol} /$ day, corresponding to about $1 \mathrm{~g}$ of potassium. The reduction of SBP after 6 and 12 weeks was -6.38 and $-3.68 \mathrm{mmHg}$, respectively. To be conservative, we used the value of SBP reduction at the end of the intervention $(-3.68 \mathrm{mmHg})$ to represent the average decrease in SBP for individuals in China. To account for the different potassium amounts ( $1 \mathrm{~g}$ in the $\mathrm{Gu}$ study vs $700 \mathrm{mg}$ in our model), and the non-linear relationship between potassium intake and blood pressure, ${ }^{23}$ we evaluated the impact at different levels (\% effectiveness) by downgrading $3.68 \mathrm{mmHg}$ to $2.76 \mathrm{mmHg}$ (75\%), $1.84 \mathrm{mmHg}(50 \%)$ and $0.92 \mathrm{mmHg}(25 \%)$.

\section{Markov model}

Finally, we built a Markov model (figure 2), based on the structure of Li et al, ${ }^{28}$ in TreeAge Pro 2015 to compare the long-term cost-effectiveness, from a societal perspective, of an additional potassium intake $(+700 \mathrm{mg} /$ day $)$, given through a milk powder product, against consumption of the same product without potassium fortification. The cost of the potassium fortification in the milk powder was modelled as a $13.13 \%$ increase (intl $\$ 0.99$ vs intl $\$ 1.12$ ). Both arms (milk powder with potassium fortification and milk powder without fortification) have the same structure, but different probabilities of CVD events.

In order to populate the model, we relied on several data sources including published literature, expert opinion, national statistics and tariff lists. The stroke and MI incidence and mortality for the milk powder without potassium fortification arm (control group), and the risk reduction applied to estimate the probabilities for the 


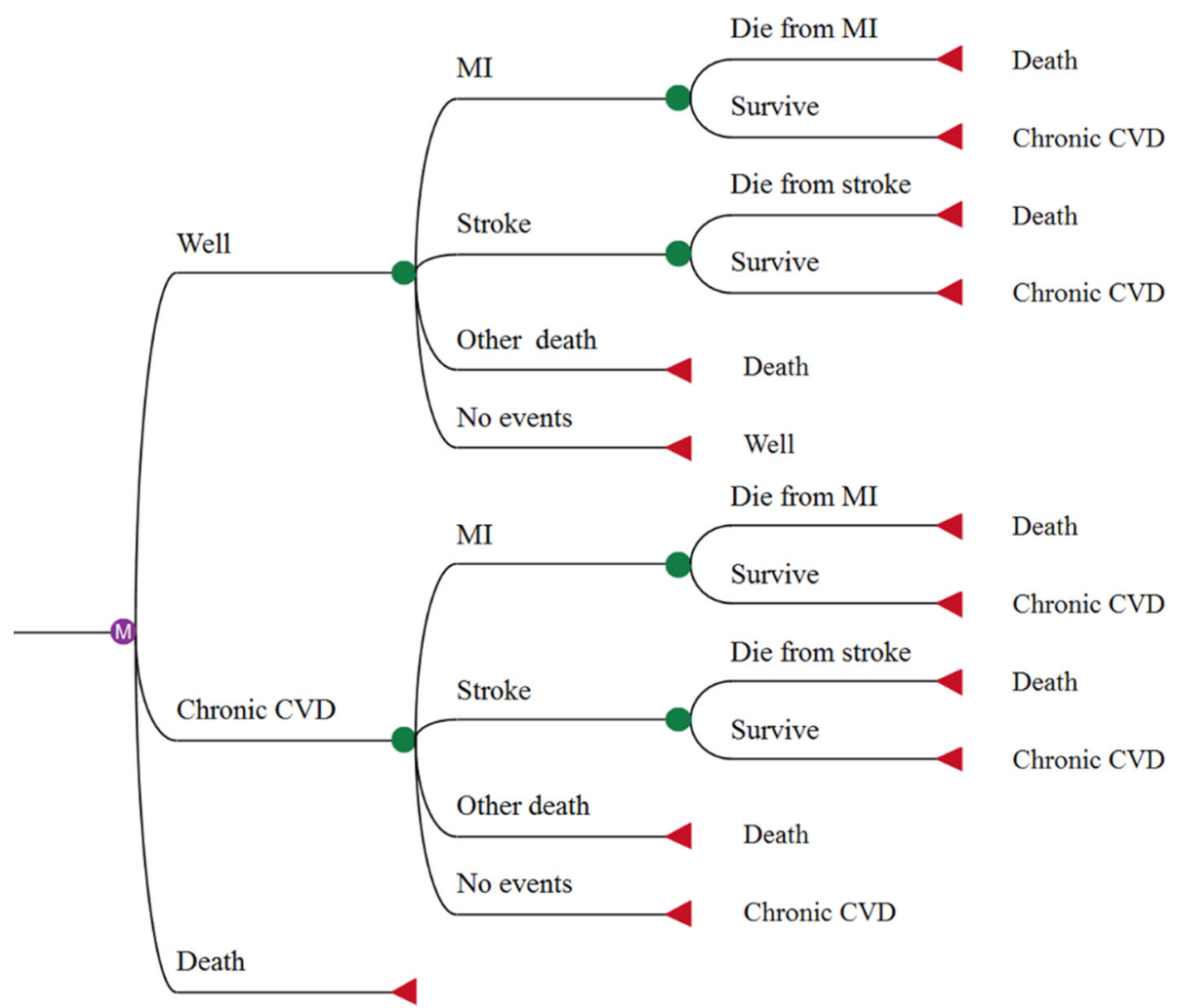

Figure 2 Decision tree representation of the Markov model structure for each arm. ${ }^{63}$ Circles indicate chance events and triangles indicate terminal nodes. The 'well" and 'chronic CVD' state represent people without or with prior AMI or stroke, respectively. For the initial population, we assigned 3.83\% to start in 'chronic CVD' state, consistent with the prevalence of CVD in China among 50-79 years old. The remaining $96.17 \%$ start from the 'well' state. People in the 'well' state can remain in their state or passing to 'chronic CVD' in case of first AMI or stroke. In each cycle, people in Well and the chronic CVD states may experience a $\mathrm{MI}$ or stroke and have the same chances to survive as the other people in their state, regardless of their personal story. 'Other death' accounts for all people who die for causes different from CVD. AMI, acute myocardial infarction; CVD, cardiovascular disease; MI, myocardial infarction.

other arm (intervention group) are reported in table 1. Given the linear relationship between SBP and CVD risk reduction, we extrapolated the impact of a $3.68 \mathrm{mmHg}$ reduction in SBP on CVD risk by dividing the referenced impact of a $10 \mathrm{mmHg}$ reduction by $2.71 .29-32$

Costs and utilities associated with a cardiovascular event are reported in table 2 . The cost of inpatient care due to a stroke was calculated as a weighted average of $25 \%$ cerebral haemorrhage and $75 \%$ cerebral infarction. The early outpatient drug cost for treating hypertension was obtained from a Chinese publication, where only two geographical areas (Beijing City and Jiangsu Province) were surveyed.$^{33}$ In order to calculate a national cost, we first calculated the average of these two provinces. Given that the outpatient drug costs were collected only in Tier 1 hospitals, we then calculated the costs in the Tier 2 and Tier 3 hospitals (which are more expensive). We obtained the total number of outpatient visits for Tier 1, Tier 2 and Tier 3 hospitals in China and average outpatient drug costs (ie, general costs, not only for hypertensive) at each tier from the China Health and Family Planning Statistical Yearbook $2015 .{ }^{34}$ We used these data to estimate the amounts Tier 1 and Tier 2 hospitals spend as compared with Tier 1 . In this way, we obtained the average outpatient drug cost per capita for hypertensive patients in all Tier hospitals in 2014. When necessary, the appropriate inflation rate was applied to convert the costs from previous years to 2014 prices. In order to estimate the societal loss due to CVD among the population of 50-79year olds, we multiplied the average daily salary for the number of days of work lost after a stroke or a MI. This was valid even for retired people, on the assumption that their time still has a value (eg, they may be involved in socially useful activities such as looking after grandchildren). All costs are expressed in international dollars. ${ }^{14}$

Utilities were obtained from the literature and were expressed in quality-adjusted life years (QALY). The utilities for MI and stroke referred to acute states (moment of the event).

Taking into account the minimum age of the population of interest ( 50 years old) and the average life expectancy in the Chinese population (76years), ${ }^{35}$ we considered a time horizon of 30 years. A discount rate of $3 \%$ per annum was applied for both costs and utilities. ${ }^{3637}$ The findings were presented as incremental cost-effectiveness ratio (ICER), which measures the incremental cost per QALY. We performed both deterministic and probabilistic sensitivity analyses to assess the impact of the 


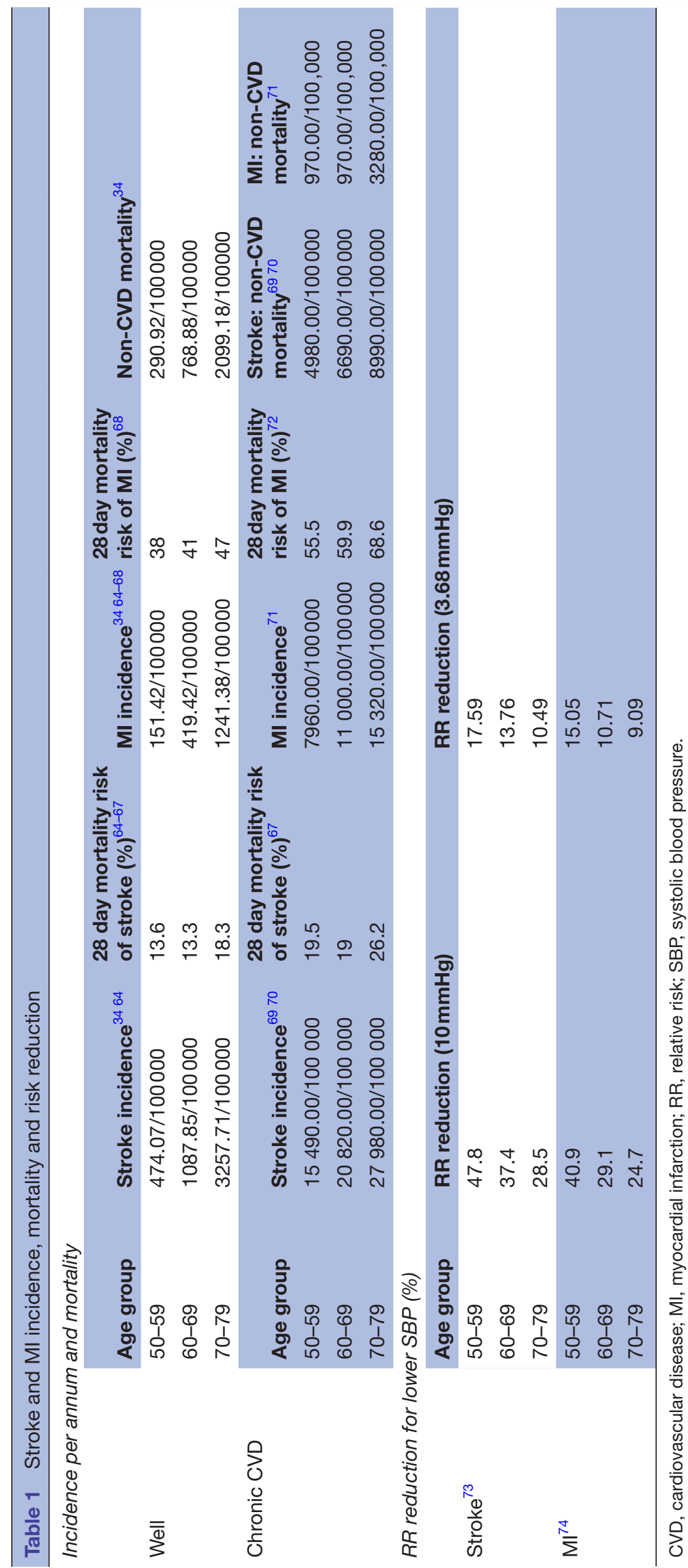

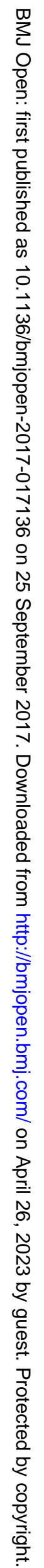


Table 2 Costs and utilities

Value Reference

\begin{tabular}{lll}
\hline Milk powders price & & Market price per serving \\
Fortified powdered milk per serving & 1.12 & Market price per serving \\
Not fortified powdered milk per serving & 0.99 & Rar
\end{tabular}

Outpatient drug costs

Beijing's total outpatient drug costs per capita for hypertensive 2186.75

patients in 2009 Tier 1 hospital

Jiangsu's total outpatient drug costs per capita for $\quad 983.99$

hypertensive patients in 2009 Tier 1 hospital

83.99

33

Average total outpatient drug costs per capita for hypertensive 1585.37

patients in 2009 Tier 1 hospital

Inflation factor from 2009 to 2014 (\%)

17

55

Average total outpatient drug costs per capita for hypertensive 1853.27

patients in 2014 Tier 1 hospital

Average drug costs in Tier 1 hospital in 2014

18.86

34

Average drug costs in Tier 2 hospital in 2014

23.52

34

Average drug costs in Tier 3 hospital in 2014

38.64

34

Average drug costs in Tier 2 hospital/average drug costs in $\quad 1.25$

Tier 1 hospital

Average drug costs in Tier 3 hospital/average drug costs in $\quad 2.05$

Tier 1 hospital

$\begin{array}{lll}\text { Outpatient visit numbers in Tier } 1 \text { hospital in } 2014 & 4790887798 & 34 \\ \text { Outpatient visit numbers in Tier } 2 \text { hospital in } 2014 & 1147086000 & 34 \\ \text { Outpatient visit numbers in Tier } 3 \text { hospital in } 2014 & 1398044000 & 34 \\ \text { Share of outpatient visit numbers in Tier } 1 \text { hospital } & 0.65 & 0.16 \\ \text { Share of outpatient visit numbers in Tier } 2 \text { hospital } & 0.19 & 2295.04 \\ \text { Share of outpatient visit numbers in Tier } 3 \text { hospital } & & \\ \text { Average total outpatient drug costs per capita for hypertensive } \\ \text { patients in 2014 All Tier hospital }\end{array}$

Hypertension screening cost and frequency

Assumed hypertension screening yearly frequency (no of visits) 1

Hypertension screening visit cost

$16.50(14.50-17.20)$

36

Inpatient costs and days

$\begin{array}{lll}\text { Inpatient MI } & 7018.75 & 34\end{array}$

$\begin{array}{lll}\text { Inpatient stroke } & 3015.191761 & 34\end{array}$

MI inpatient days

$11(7-15)$

Stroke inpatient days

28 (23 not insured-32 insured) 76

Chronic costs

$\begin{array}{lll}\text { Chronic cost for the rest of year 1 MI } & 1060 & 36 \\ \text { Chronic cost for the rest of year 1 stroke } & 650 & 36 \\ \text { Annual chronic cost after year 1 MI } & 740 & 36 \\ \text { Annual chronic cost after year 1 stroke } & 420 & 55 \\ \text { ndirect costs } & 13246.87 & 365-\text { weekends-11 national } \\ \text { GDP per capita 2014 } & 250 & \text { holidays } \\ \text { Working days per year } & 53 & \text { GDP per capita/working } \\ \text { days }\end{array}$

Continued 
Table 2 Continued

\begin{tabular}{lll}
\hline & Value & Reference \\
\hline Discount (\%) & & \\
$\quad$ Annual discount rate for costs and QALYs (\%) & 3 & $(37,36)$ \\
Utilities (QALY) & & 36 \\
MI & 0.58 & 36 \\
Stroke & 0.7 & 39 \\
Chronic CVD & 0.872 & 36 \\
Death & 0 & 36 \\
Well & 1 & 36 \\
\hline
\end{tabular}

CVD, cardiovascular disease; GDP, gross domestic product; intl\$, international dollar; MI, myocardial infarction; QALY, quality-adjusted life year; RMB, Renminbi.

uncertainty of the key variables in the model on the base case estimates. This study did not involve human subjects and thereby was exempt from institutional review board approval.

\section{RESULTS}

\section{Cost-Effectiveness}

With an ICER equal to int $\$ 4711.56$ per QALY gained, the intervention can be classified as very cost-effective according to the conventional WHO threshold which accounts for a country's annual gross domestic product (GDP) per capita (very cost-effective if $<1$ GDP per capita; cost-effective if equal to 1-3 GDP per capita; no cost-effective is $>3$ GDP per capita). ${ }^{38}$ Moreover, we evaluated the impact on the base case estimates of an increase in potassium intake $(+700 \mathrm{mg} /$ day $)$ at different level of effectiveness $(75 \%, 50 \%$ and $25 \%)$ on SBP. The consumption of milk powder fortified with potassium was the preferred strategy compared with the milk powder without fortification, ceteris paribus, up to an effectiveness of potassium on SBP equal to the $50 \%$ (table 3 ).

\section{Sensitivity analyses}

We performed both deterministic and probabilistic sensitivity analysis evaluating the impact on the base case estimates of an increase in potassium intake $(+700 \mathrm{mg} /$ day $)$ at different level of effectiveness (75\%, 50\% and 25\%) on SBP.

In the deterministic sensitivity analysis (Tornado diagrams, figure 3 ), we applied $\pm 20 \%$ variations to all costs and the appropriate ranges (table 2) to the inpatient days of MI and stroke. Hospitalisation after a stroke had the largest impact whereas a hypertension visit had the least impact on final costs.

In the probabilistic sensitivity analysis (Monte Carlo simulations, figure 4), all costs and resources used were modelled using a gamma distribution, while probabilities and utilities using a beta distribution. ${ }^{39}$ The consumption of milk powder fortified with potassium was the preferred strategy compared with the milk powder without fortification, ceteris paribus, up to an effectiveness of potassium on SBP equal to $-1.83 \mathrm{mmHg}(49.72 \%)$. The results were overall robust.

\section{DISCUSSION \\ Principal findings}

To the best of our knowledge, this study is the first to show the cost-effectiveness of increasing potassium intake, via a milk powder product fortified with potassium $(+700 \mathrm{mg} /$ day), to reduce blood pressure and prevent cardiovascular diseases in China. This model capitalises on the

\begin{tabular}{|c|c|c|c|c|c|c|}
\hline Effectiveness on SBP & Strategy & Cost & Incremental cost & QALY & Incremental QALY & ICER \\
\hline \multirow[t]{2}{*}{$100 \%(3.68 \mathrm{mmHg})$} & Milk not fortified & 18518.43 & 1234.07 & 16.27 & 0.26 & 4711.56 \\
\hline & Milk fortified & 19752.5 & & 16.53 & & \\
\hline \multirow[t]{2}{*}{$75 \%(2.76 \mathrm{mmHg})$} & Milk not fortified & 18518.43 & 1321.2 & 16.27 & 0.2 & 6734.10 \\
\hline & Milk fortified & 19839.63 & & 16.47 & & \\
\hline \multirow[t]{2}{*}{$50 \%(1.84 \mathrm{mmHg})$} & Milk not fortified & 18518.43 & 1406.43 & 16.27 & 0.13 & 10767.12 \\
\hline & Milk fortified & 19924.86 & & 16.40 & & \\
\hline \multirow[t]{2}{*}{$25 \%(0.92 \mathrm{mmHg})$} & Milk not fortified & 18518.43 & 1489.8 & 16.27 & 0.07 & 22842.90 \\
\hline & Milk fortified & 20008.23 & & 16.33 & & \\
\hline
\end{tabular}

ICER, incremental cost-effectiveness ratio; QALY, quality-adjusted life year; SBP, systolic blood pressure. 


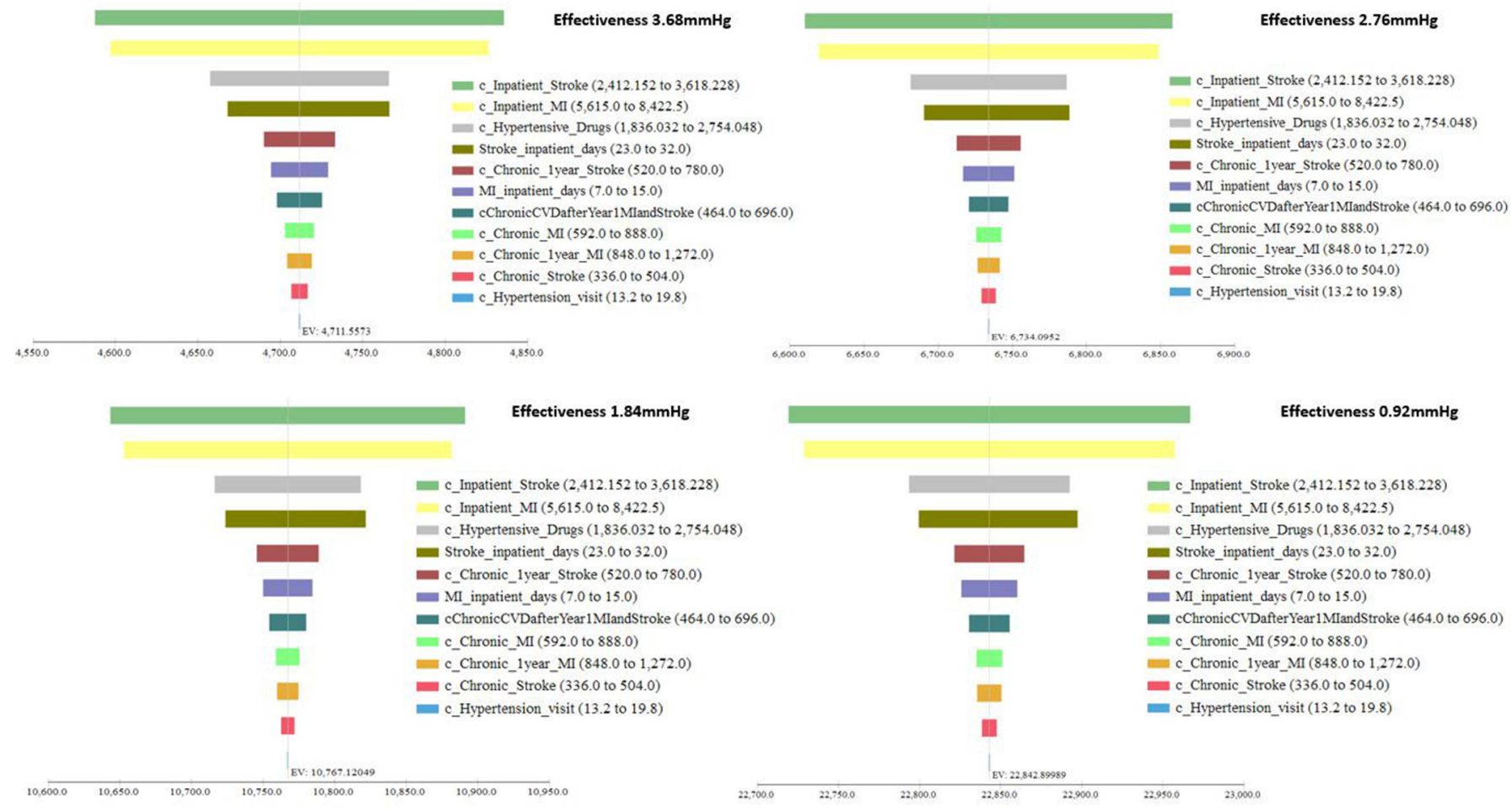

Figure 3 Deterministic sensitivity analysis - Tornado diagrams. The bars represent the relative importance of the variables on the expected value (EV), the incremental cost-effectiveness ratio: the larger the bar, the higher the impact of that cost voice. In this case the cost of the hypertensive drugs is the one affecting the final cost the most, the hypertension visit the less. CVD, cardiovascular disease; MI, myocardial infarction.

substantial evidence already existing on the association between increased potassium intake and the reduction of blood pressure. ${ }^{23} 40$ The daily potassium intake we used as baseline, $1.785 \mathrm{~g} /$ day, is consistent with the values reported in the literature: $1.7 \mathrm{~g} /$ day and $1.8 \mathrm{~g} /$ day. ${ }^{41}{ }^{42}$ It is worth to mention that, in their subgroup analyses, Aburto et al showed that, regardless of baseline potassium intake, there is a comparable reduction in blood pressure when potassium intake is increased. ${ }^{23}$

We estimated that an increase in potassium intake $(+700 \mathrm{mg} /$ day $)$, would result in an average reduction in SBP of $3.68 \mathrm{mmHg}$ in the Chinese adult population. This value was based on an intervention study conducted in Chinese adults (mean age: $56.9 \pm 7.4$ in the intervention group $)^{27}$ with an overall low risk of bias, ${ }^{43}$ which has been included in several recent systematic reviews and meta-analyses. ${ }^{23} 40$ The baseline SBP was $130-159 \mathrm{mmHg}$, which is consistent with other reported figures from the literature for a similar age range. ${ }^{44}$ In that specific study, the difference in 24 hours urinary excretion of potassium between intervention and control group was $20.6 \mathrm{mmol}$, hence corresponding to an estimated intake of $1.0 \mathrm{~g}$ of potassium (close to our own case), assuming a recovery of $80 \%$ of dietary potassium in the urine. This value is in agreement with the reduction in SBP reported in the Aburto meta-analysis of $3.49 \mathrm{mmHg}$ (95\% CI: 1.82 to 5.15) on average for the overall population. ${ }^{23}$ Moreover, when the difference in achieved potassium intake between the intervention and the control group was less than
$30 \mathrm{mmol} /$ day $(1.17 \mathrm{~g} /$ day $)$, a reduction of $4.89 \mathrm{mmHg}$ in SBP (95\% CI: 2.20 to 7.59 ) was observed..$^{23}$ It is well acknowledged that BP status at baseline as well as age influence the reduction in the blood pressure triggered by potassium intake, with much larger effects observed in hypertensive compared with non-hypertensive individuals, ${ }^{23}$ and in older compared with younger individuals. ${ }^{26}$ Also, blood pressure may be significantly lowered in normotensive subjects with a low dietary intake of potassium, ${ }^{45}$ or with sodium sensitivity, an independent risk factor for cardiovascular disease. ${ }^{46}$ We are therefore confident that both normotensive and hypertensive would equally benefit from a potassium supplementation.

Unfortunately, no other study has been conducted with such a small amount of potassium like ours $(+700 \mathrm{~g} /$ day $)$, therefore we could not model the provincial level variation impact. Acknowledging these limitations, we took uncertainty into consideration through an extended sensitivity analysis, to model which would be the effect at different level of effectiveness on SBP $(100 \%, 75 \%, 50 \%$, $25 \%$ and $10 \%)$.

\section{Strengths and weaknesses of the study}

The main strength of this study was the conservative approach adopted. The cost-effectiveness model only included stroke and MI among the possible cardiovascular events, focused only on medical costs and partially on indirect costs (days of work lost), and did not include other cost types such as travelling costs, mortality costs 

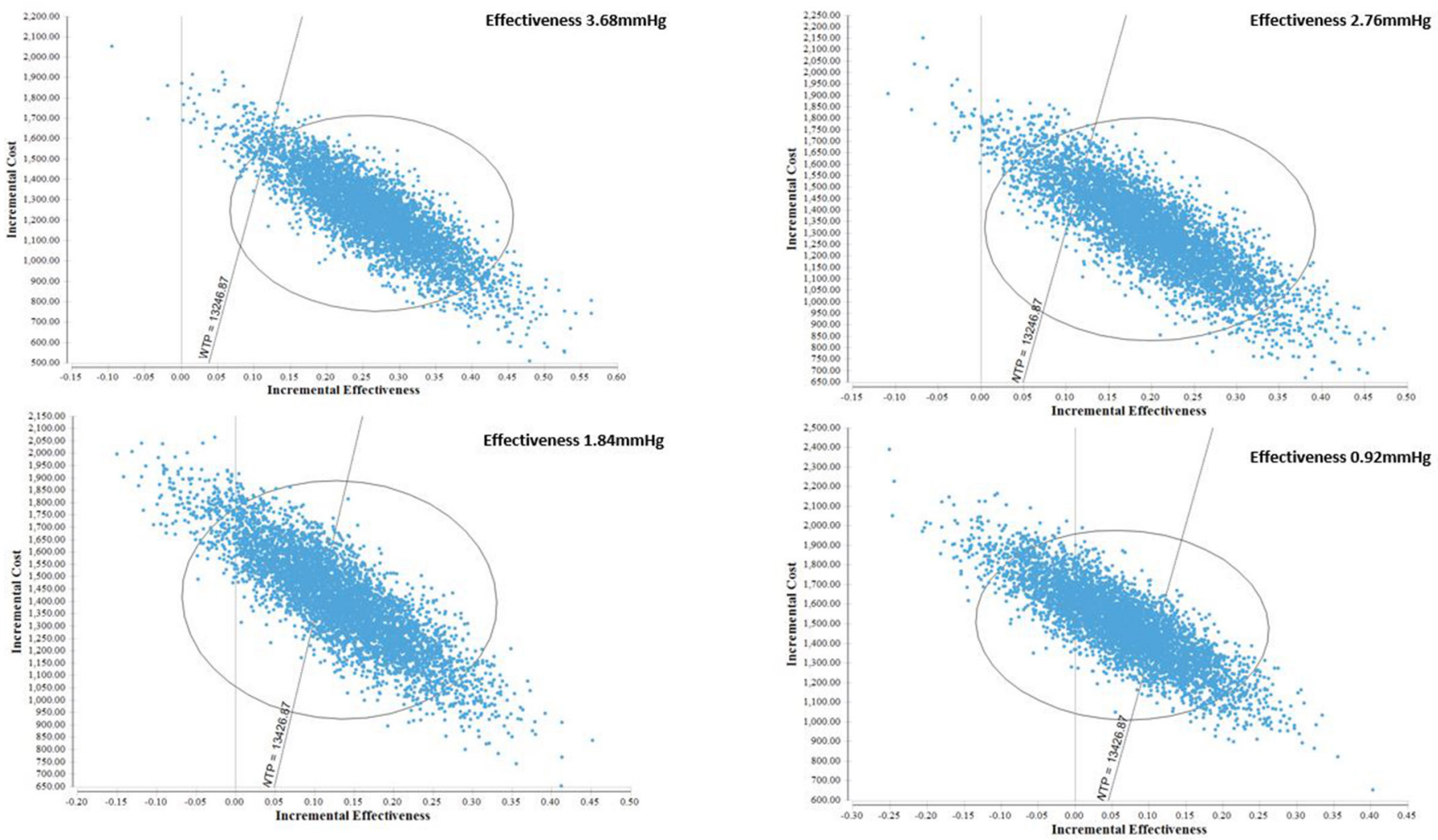

Figure 4 Probabilistic sensitivity analysis-Monte Carlo simulations. The $\mathrm{x}$ and y axes, respectively, represent the incremental effectiveness and cost. The dots represent the incremental cost-effectiveness ratio values outcome of 5000 simulations carried out to take into consideration the uncertainty around both cost and effectiveness. The ellipse represents $95 \%$ of all data points. The line from the origin is the willingness to pay (WTP), corresponding to the gross domestic product per capita. Points below right of the WTP line recommend the fortified milk powder as preferred strategy and are $96.32 \%$ for $3.68 \mathrm{mmHg}(100 \%$ effectiveness), $86.24 \%$ for $2.76 \mathrm{mmHg}$ (75\% effectiveness), $61.34 \%$ for $1.84 \mathrm{mmHg}$ (50\% effectiveness) and $30.72 \%$ for 0.92 $\mathrm{mmHg}(25 \%$ effectiveness).

or intangible costs. An additional strength was the extensive sensitivity analysis conducted on the effectiveness of a potassium supplementation to decrease SBP which evaluated several scenarios given that limited clinical evidence is available in this population. To the best of our knowledge, interventions have not been conducted using relatively small amounts $(700 \mathrm{mg} /$ day $)$ of potassium, but given that potassium fortification may also make foods bitter, this is the maximum amount consumers showed to tolerate during consumers tastes. An additional amount would mean to risk to have a negative impact on the compliance and, as a consequence, on the effectiveness, of such an intervention.

The first limitation of this study was the use of multiple sources of data for the model parameter values.

Unfortunately, no data exist about CVD risk or burden of the Chinese 50-79year olds who regularly drink milk compared with those who do not. Moreover, given the lack of detailed information about some provinces and ethnic groups, we assumed that incidences, costs and baseline BP and potassium intakes were the same across China in order to extend our results to a national level. For the same reason, we assumed people who never had a CVD event to be fully healthy and do not face any cost to treat hypertension. Finally, we did not consider the current sodium intake nor any effect of fortified milk consumption on sodium consumption. The sodium to potassium ratio regulates blood pressure and Chinese population consume excessive amounts of sodium and not enough potassium. Therefore, increasing potassium intake would be indeed more effective in preventing cardiovascular diseases if combined with a reduction in the salt consumption.

\section{Comparison with other studies}

Multiple cardiovascular risk factors are common among the Chinese population, including smoking or overweight, and often both are present in the same individual. ${ }^{3}{ }^{47} \mathrm{~A}$ large body of literature exists on interventions aiming to reduce blood pressure ${ }^{48}{ }^{49}$ the most important individual risk factor for CVD, with some studies assessing the effectiveness and cost-effectiveness of the interventions. ${ }^{50} 51$ One study from $\mathrm{He} e t \mathrm{al}$, targeted to families of the Chinese schoolchildren in the Changzhi urban area, evaluated an education programme to lower-salt intake,${ }^{17}$ while a study from Wang et al simulated which would be the effect of promoting the replacement of the cooking salt with a substitute, currently available, containing $25 \%$ potassium and $10 \%$ magnesium in the Chinese diet. ${ }^{44}$ Both studies analyse the impact of a culturally tailored intervention: 
differently from North American and European population, who take the most of their salt intake from packaged processed food, Chinese population primary salt intake is food consumed at home, therefore home-cooked foods is what public policies should target. ${ }^{44}$ Another study from $\mathrm{Gu}$ et al simulated the effect of a hypertension treatment of essential medicines in Chinese adults and evaluated different healthcare scenarios. ${ }^{36}$ Similar to the He et al study, ${ }^{17}$ the present analysis evaluated the effectiveness of a SBP reduction through food, and similar to $\mathrm{Gu}$ and Wang study, ${ }^{364}$ it was based on a simulation model and not a real intervention. Simulations allow generalising the results to the whole country, but are less precise than a real intervention. All studies, however, had a positive outcome and showed the effectiveness and/or cost-effectiveness of the interventions. Together with our findings, these results suggest that in China different interventions (less sodium, more potassium and appropriate medicines) could be implemented to decrease blood pressure and lower the risk of CVD.

While consistent evidence exists in China, studies evaluating the effect of fortifying food to decrease the risk of CVD have had mixed findings in Europe. In a study from Germany, an enriched margarine with plant sterols has been shown to be a cost-effective method to decrease the risk of coronary heart disease (CHD) in a representative sample of the 30-79year olds population; assuming a health insurer's perspective and calculating the transition probabilities for CHD and CHD-related death on the basis of the Framingham risk equations. ${ }^{52}$ In a study from the Netherlands, they evaluated the cost-effectiveness of functional foods containing phytosterols/phytostanols, in addition to statins, to prevent cardiovascular diseases among the population of 35-75year old eligible for use according to their 10-year absolute risk of fatal cardiovascular disease (SCORE risk) ${ }^{53}$ The results, differently from the German study, ${ }^{52}$ showed that this strategy was not- cost-effective.

A lack of consistency in the findings between China and Europe could be due to differences in the type of intervention (margarine and functional food containing phytosterols/phytostanols vs potassium/sodium), the health outcomes (cholesterol vs SBP), the healthcare systems and the health status of the populations.

\section{Public health implications}

In China, and like many other developing countries, the rapid rise of non-communicable diseases imposes major challenges to the healthcare system and targeting high blood pressure is a public policy priority. ${ }^{54}$ Adults in China consume excessive amounts of sodium and not enough potassium. Both are key minerals involved in the regulation of blood pressure; therefore, increasing potassium intake, in combination with other public health interventions, may help in decreasing blood pressure and preventing cardiovascular diseases. ${ }^{2342}$

According to our findings, the consumption of milk powder fortified with potassium was cost-effective, if compared with the milk powder without fortification, for the $8.67 \%$ of $50-79$ year olds who regularly consume milk, ${ }^{20} 21$ and could have a beneficial impact without increasing the total caloric intake. Healthcare savings due to CVD prevention would amount to intl\$267.54 per consumer. Given a total population of 362.74 million in that age range,${ }^{55}$ the consumption of milk powder fortified with potassium could allow medical cost savings equal to intl\$8.41 billion. In addition, out-of-pocket expenditures are well known to be a substantial portion of the healthcare costs and a large portion of the population in China is not covered by insurance. In 2003, approximately $56 \%$ of CVD patients did not have health insurance and on average, $76 \%$ of outpatient costs per visit and $65 \%$ of inpatient costs were paid out-of-pocket. ${ }^{56}$ Indeed, individuals experiencing severe CVD are likely to face catastrophic health spending (CHS), defined as health expenditures higher than $30 \%-40 \%$ of the total household budget. ${ }^{5758}$ In a 2009 survey involving 62 hospitals in China, more than the $71 \%$ of poststroke patients reported CHS, which results in impoverishment for individuals and their families. ${ }^{59}$ Recent healthcare reforms are aimed towards improving this situation and reducing inequalities, but further strategies are still needed for patients with cardiovascular disease; especially for those living in rural areas or belonging to lower income groups. ${ }^{60-62}$

\section{Unanswered questions and future research}

Further research is needed to assess the cost-effectiveness of reducing CVD risk with other types of foods and new clinical trials are encouraged to evaluate the effectiveness of small increases in potassium intake on the SBP.

\section{CONCLUSION}

Together with other preventive interventions, the consumption of a milk powder fortified with potassium could represent a cost-effective strategy to attenuate the rapid rise in cardiovascular burden among the 50-79 year olds in China. This strategy could be especially easy to implement in those already having regular dairy consumption, and even encouraged in those with low dairy product intake.

Acknowledgements We thank Dr Dantong Wang (Nestlé Research Center, Lausanne, Switzerland) for the help provided in translating and interpreting some of the Chinese literature analysed and Dr Kevin Mathias (Nestlé Research Center, Lausanne, Switzerland) for the language revision of the final manuscript. Finally, since this research used data from CHNS, we thank the National Institute for Nutrition and Health, China Center for Disease Control and Prevention, Carolina Population Center (P2C HD050924 and T32 HD007168), the University of North Carolina at Chapel Hill, the National Institutes of Health (NIH) (R01-HD30880, DK056350, R24 HD050924 and R01-HD38700) and the NIH Fogarty International Center (D43 TW009077, D43 TW007709) for financial support for the CHNS data collection and analysis files from 1989 to 2015 and future surveys, and the ChinaJapan Friendship Hospital, Ministry of Health for support for CHNS 2009, Chinese National Human Genome Center at Shanghai since 2009 and Beijing Municipal Center for Disease Prevention and Control since 2011.

Contributors PD conceived the study. LD built the model and drafted the paper. $\mathrm{HF}$ and TX updated the economic model with demographic, cost and utilities and helped in running the model; YW and ML contributed with epidemiological data 
and estimates; both HF and YW oversaw and supervised the empirical work. DZ supervised and contributed to everything (data, effectiveness, writing) related to the potassium effectiveness on systolic blood pressure and consequent risk reduction. All authors contributed with their comments to the manuscript and revised the final version of the paper.

Funding This work was funded by the Nestlé Research Center of Beijing (China) and the Nestlé Research Center of Lausanne (Switzerland).

Competing interests HF and YW were paid as consultants by Nestlé.

Provenance and peer review Not commissioned; externally peer reviewed.

Data sharing statement Requests for access to data should be made to the corresponding author at patrick.detzel@rdls.nestle.com.

Open Access This is an Open Access article distributed in accordance with the Creative Commons Attribution Non Commercial (CC BY-NC 4.0) license, which permits others to distribute, remix, adapt, build upon this work non-commercially, and license their derivative works on different terms, provided the original work is properly cited and the use is non-commercial. See: http://creativecommons.org/ licenses/by-nc/4.0/

(C) Article author(s) (or their employer(s) unless otherwise stated in the text of the article) 2017. All rights reserved. No commercial use is permitted unless otherwise expressly granted.

\section{REFERENCES}

1. Mendis S, Puska P, Norrving B, et al. World Health Organization (in collaboration with the World Heart Federation and World Stroke Organization). Global atlas on Cardiovascular Disease Prevention and Control. Geneva, 2011.

2. World Health Organization. WHOCardiovascular diseases (CVDs): Fact sheet $N^{\circ} 317:$, 2015.

3. Wu Y, Benjamin EJ, MacMahon S, et al. Prevention and Control of Cardiovascular Disease in the Rapidly Changing Economy of China. Circulation 2016;133:2545-60.

4. Bundy JD, He J. Hypertension and Related Cardiovascular Disease Burden in China. Ann Glob Health 2016;82:227-33.

5. Li Y, Wang DD, Ley SH, et al. Potential Impact of Time Trend of LifeStyle Factors on Cardiovascular Disease Burden in China. J Am Coll Cardiol 2016;68:818-33.

6. Xu G, Liu J, Liu S, et al. The expanding burden of elevated blood pressure in China: evidence from Jiangxi Province, 2007-2010. Medicine 2015;94:e1623.

7. Anderson CA, Appel LJ, Okuda N, et al. Dietary sources of sodium in China, Japan, the United Kingdom, and the United States, women and men aged 40 to 59 years: the INTERMAP study. J Am Diet Assoc 2010;110:736-45.

8. He FJ, Wu Y, Ma J, et al. A school-based education programme to reduce salt intake in children and their families (School-EduSalt): protocol of a cluster randomised controlled trial. BMJ Open 2013;3:e003388.

9. Zhao L, Stamler J, Yan LL, et al. Blood pressure differences between northern and southern Chinese: role of dietary factors. Hypertension 2004;43:1332-7.

10. Tsai CF, Thomas B, Sudlow CL, et al. Epidemiology of stroke and its subtypes in Chinese vs white populations: a systematic review. Neurology 2013;81:264-72.

11. Wang S, Petzold M, Cao J, et al. Direct medical costs of hospitalizations for cardiovascular diseases in Shanghai, China: trends and projections. Medicine 2015;94:e837.

12. World Health Organization. W.P.R.O. Cardiovascular diseases: WHO, 2016.

13. Moran $A, G u D$, Zhao D, et al. Future cardiovascular disease in China. Circ Cardiovasc Qual Outcomes 2010:109.

14. World Bank. PPP conversion factor, GDP (LCU per international \$). World Bank, 2016.

15. Gaziano TA. Reducing the growing burden of cardiovascular disease in the developing world. Health Aff 2007;26:13-24.

16. World Health Organization. WHO issues new guidance on dietary salt and potassium.note for the media: WHO, 2013.

17. He FJ, Wu Y, Feng XX, et al. School based education programme to reduce salt intake in children and their families (School-EduSalt): cluster randomised controlled trial. BMJ 2015;350:h770.

18. Gijsbers L, Dower JI, Schalkwijk CG, et al. Effects of sodium and potassium supplementation on endothelial function: a fully controlled dietary intervention study. Br J Nutr 2015;114:1419-26.
19. Inaba Y, Chen JA, Bergmann SR, et al. Prediction of future cardiovascular outcomes by flow-mediated vasodilatation of brachial artery: a meta-analysis. Int J Cardiovasc Imaging 2010;26:631-40.

20. China Health and Nutrition Survey, 2009.

21. Creme Global. Predictive intake modelling: Creme Global, 2015.

22. World Health Organization. Effect of increased potassium intake on cardiovascular disease, coronary heart disease and stroke: WHO, 2012.

23. Aburto $\mathrm{NJ}$, Hanson S, Gutierrez $\mathrm{H}$, et al. Effect of increased potassium intake on cardiovascular risk factors and disease: systematic review and meta-analyses. BMJ 2013;346:f1378.

24. Cappuccio FP, MacGregor GA. Does potassium supplementation lower blood pressure? A meta-analysis of published trials. $J$ Hypertens 1991;9:465-73.

25. Whelton PK, He J, Cutler JA, et al. Effects of oral potassium on blood pressure. Meta-analysis of randomized controlled clinical trials. JAMA 1997;277:1624-32.

26. Geleijnse JM, Kok FJ, Grobbee DE, et al. Blood pressure response to changes in sodium and potassium intake: a metaregression analysis of randomised trials. J Hum Hypertens 2003;17:471-80.

27. Gu D, He J, Wu X, et al. Effect of potassium supplementation on blood pressure in Chinese: a randomized, placebo-controlled trial. $J$ Hypertens 2001;19:1325-31.

28. Li X, Jan S, Yan LL, et al. Cost and cost-effectiveness of a schoolbased education program to reduce salt intake in children and their families in China. PLoS One 2017;12:e0183033.

29. Gu D, He J, Coxson PG, et al. The cost-effectiveness of low-cost essential antihypertensive medicines for hypertension control in China: a modelling study. PLoS Med 2015;12:e1001860.

30. Lewington S, Clarke R, Qizilbash N, et al. Age-specific relevance of usual blood pressure to vascular mortality: a meta-analysis of individual data for one million adults in 61 prospective studies. Lancet 2002;360:1903-13.

31. MacMahon S, Peto R, Cutler J, et al. Blood pressure, stroke, and coronary heart disease. Part 1, Prolonged differences in blood pressure: prospective observational studies corrected for the regression dilution bias. Lancet 1990;335:765-74.

32. Eastern Stroke Coronary Heart Disease Collaborative Research. blood pressure, cholesterol, and stroke in Eastern Asia. Lancet 1998;352:p1801-7.

33. Xiong J, Chen $\mathrm{K}$, Xiong $\mathrm{X}$, et al. Analysis of the cost and influence factors urban hypertensive patients in China. Chinese Health Economics 2010;29:81-3.

34. National Health and Family Planning Commission. China Health and Family Planning Statistical Yearbook. Beijing, China: China Union Medical University Press, 2015. (Epub ahead of 2016).

35. World Bank (2016). Life expectancy at birth: World Bank, 2016.

36. Gu D, Kelly TN, Wu X, et al. Blood pressure and risk of cardiovascular disease in Chinese men and women. Am J Hypertens 2008;21:265-72.

37. Drummond MF. Methods for the Economic evaluation of Health Care Porgrammes. Oxford: O.U. Press. Editor, 2005.

38. World Health Organization. Cost effectiveness and strategic planning WHO-CHOICE: WHO, 2016.

39. Tengs TO, Wallace A. One thousand health-related quality-of-life estimates. Med Care 2000;38:583-637.

40. Binia A, Jaeger J, Hu Y, et al. Daily potassium intake and sodium-topotassium ratio in the reduction of blood pressure: a meta-analysis of randomized controlled trials. J Hypertens 2015;33:1509-20.

41. van Mierlo LA, Greyling A, Zock PL, et al. Suboptimal potassium intake and potential impact on population blood pressure. Arch Intern Med 2010;170:1501-2.

42. Du S, Neiman A, Batis C, et al. Understanding the patterns and trends of sodium intake, potassium intake, and sodium to potassium ratio and their effect on hypertension in China. Am J Clin Nutr 2014;99:334-43.

43. World Health Organization. Effect of increased potassium intake on blood pressure, renal function, blood lipids and other potential adverse effects: WHO, 2012.

44. Wang M, Moran AE, Liu J, et al. Projected Impact of Salt Restriction on Prevention of Cardiovascular Disease in China: A Modeling Study. PLoS One 2016;11:e0146820.

45. Sacks FM, Willett WC, Smith A, et al. Effect on blood pressure of potassium, calcium, and magnesium in women with low habitual intake. Hypertension 1998;31:131-8.

46. Morris RC, Sebastian A, Forman A, et al. Normotensive salt sensitivity: effects of race and dietary potassium. Hypertension 1999;33:18-23.

47. Yang ZJ, Liu J, Ge JP, , et al. Prevalence of cardiovascular disease risk factor in the chinese population: the 2007-2008 China National Diabetes and metabolic disorders study. Eur Heart J 2012;33:ehr205. 
48. Yan L, Li N, Wu Y. Salt restriction and challenges in China for hypertension control. Curr Cardiovasc Risk Rep 2011;5:180-6.

49. Li N, Yan LL, Niu W, et al. A large-scale cluster randomized trial to determine the effects of community-based dietary sodium reduction-the China Rural Health Initiative Sodium Reduction Study. Am Heart J 2013;166:815-22.

50. Bai $Y, Z$ hao $Y$, Wang G, et al. Cost-effectiveness of a hypertension control intervention in three community health centers in China. $J$ Prim Care Community Health 2013;4:195-201.

51. Wang X, Li W, Li X, et al. Effects and cost-effectiveness of a guideline-oriented primary healthcare hypertension management program in Beijing, China: results from a 1-year controlled trial. Hypertens Res 2013;36:313-21.

52. Gerber A, Evers T, Haverkamp H, et al. Cost-benefit analysis of a plant sterol containing low-fat margarine for cholesterol reduction. Eur J Health Econ 2006;7:247-54.

53. Eussen SR, Feenstra TL, Toxopeus IB, et al. Costs and health effects of adding functional foods containing phytosterols/-stanols to statin therapy in the prevention of cardiovascular disease. Eur J Pharmacol 2011;668:S91-S100.

54. Yang G, Wang Y, Zeng Y, et al. Rapid health transition in China, 19902010: findings from the Global Burden of Disease Study 2010. Lancet 2013:381:1987-2015.

55. National Bureau of Statistics of China. China Statistical Yearbook: China Statistics Press, 2015.

56. Yang L, Wu M, Cui B, et al. Economic burden of cardiovascular diseases in China. Expert Rev Pharmacoecon Outcomes Res 2008;8:349-56.

57. Huffman MD, Rao KD, Pichon-Riviere A, et al. A cross-sectional study of the microeconomic impact of cardiovascular disease hospitalization in four low- and middle-income countries. PLoS One 2011;6:e20821.

58. Wang Q, Liu H, Lu ZX, et al. Role of the new rural cooperative medical system in alleviating catastrophic medical payments for hypertension, stroke and coronary heart disease in poor rural Areas of China. BMC Public Health 2014;14:1.

59. Heeley E, Anderson CS, Huang Y, et al. Role of health insurance in averting economic hardship in families after acute stroke in China. Stroke 2009;40:2149-56.

60. Sun J, Liabsuetrakul T, Fan Y, et al. Protecting patients with cardiovascular diseases from catastrophic health expenditure and impoverishment by health finance reform. Trop Med Int Health 2015;20:1846-54.

61. Jiang $\mathrm{C}, \mathrm{Ma} \mathrm{J}$, Zhang $\mathrm{X}$, et al. Measuring financial protection for health in families with chronic conditions in rural China. BMC Public Health 2012;12:1.
62. Kawabata K, Xu K, Carrin G, et al. Preventing impoverishment through protection against catastrophic health expenditure. Bull World Health Organ 2002;80:612.

63. Yang ZJ, Liu J, Jp G, et al. China National Diabetes and metabolic disorders Study Group. prevalence of cardiovascular disease risk factor in the chinese population: the 2007-2008 China National Diabetes and Metabolic Disorders Study. Eur Heart $J$ 2012;33:213-20.

64. Wu Z, Yao C, Zhao D, et al. Epidemiological study on incidence and mortality of stroke in China. Chin J Epidemiol 2003;24:236-9.

65. Zhang LF, Yang J, Hong Z, et al. Proportion of different subtypes of stroke in China. Stroke 2003;34:2091-6.

66. Zhao D, Liu J, Wang W, et al. Epidemiological transition of stroke in China: twenty-one-year observational study from the Sino-MONICABeijing project. Stroke 2008;39:1668-74.

67. Sun J, Zhao D, Wang W, et al. The changing case-fatality of acute stroke in Beijing during 1984-2000. Chin J Intern Med 2007;46:362-5.

68. Moran A, Zhao D, Gu D, et al. The future impact of population growth and aging on coronary heart disease in China: projections from the Coronary Heart Disease Policy Model-China. BMC Public Health 2008;8:394

69. Wong $\mathrm{KS}$, $\mathrm{Li} \mathrm{H}$. Long-term mortality and recurrent stroke risk among Chinese stroke patients with predominant intracranial atherosclerosis. Stroke 2003;34:2361-6.

70. Delcourt C, Hackett M, Wu Y, et al. Determinants of quality of life after stroke in China: the ChinaQUEST (QUality Evaluation of Stroke care and Treatment) study. Stroke 2011;42:433-8.

71. Li S, Wu Y, Du X, et al. Rational and design of a stepped-wedge cluster randomized trial evaluating quality improvement initiative for reducing cardiovascular events among patients with acute coronary syndromes in resource-constrained hospitals in China. Am Heart J 2015;169:349-55.

72. Cap C, Ren J Li S , et al. Risk factors and in-hospital prognosis of recurrent acute myocardial infarction. Chin J Mult Organ Dis Elderly 2013;12:116-9.

73. Lawes CM, Rodgers A, Bennett DA, et al. Blood pressure and cardiovascular disease in the Asia Pacific region. $J$ Hypertens 2003;21:707-16.

74. Singh GM, Danaei G, Farzadfar F, et al. The age-specific quantitative effects of metabolic risk factors on cardiovascular diseases and diabetes: a pooled analysis. PLoS One 2013;8:e65174.

75. Li Q, Lin Z, Masoudi FA, et al. National trends in hospital length of stay for acute myocardial infarction in China. BMC Cardiovasc Disord 2015;15:9.

76. Tu F, Tokunaga S, Deng Z, et al. Analysis of hospital charges for cerebral infarction stroke inpatients in Beijing, People's Republic of China. Health Policy 2002;59:243-56. 